\title{
Efficacy of Neoadjuvant Chemotherapy for Synovial Sarcoma: Retrospective Analysis of a Nationwide Database in Japan
}

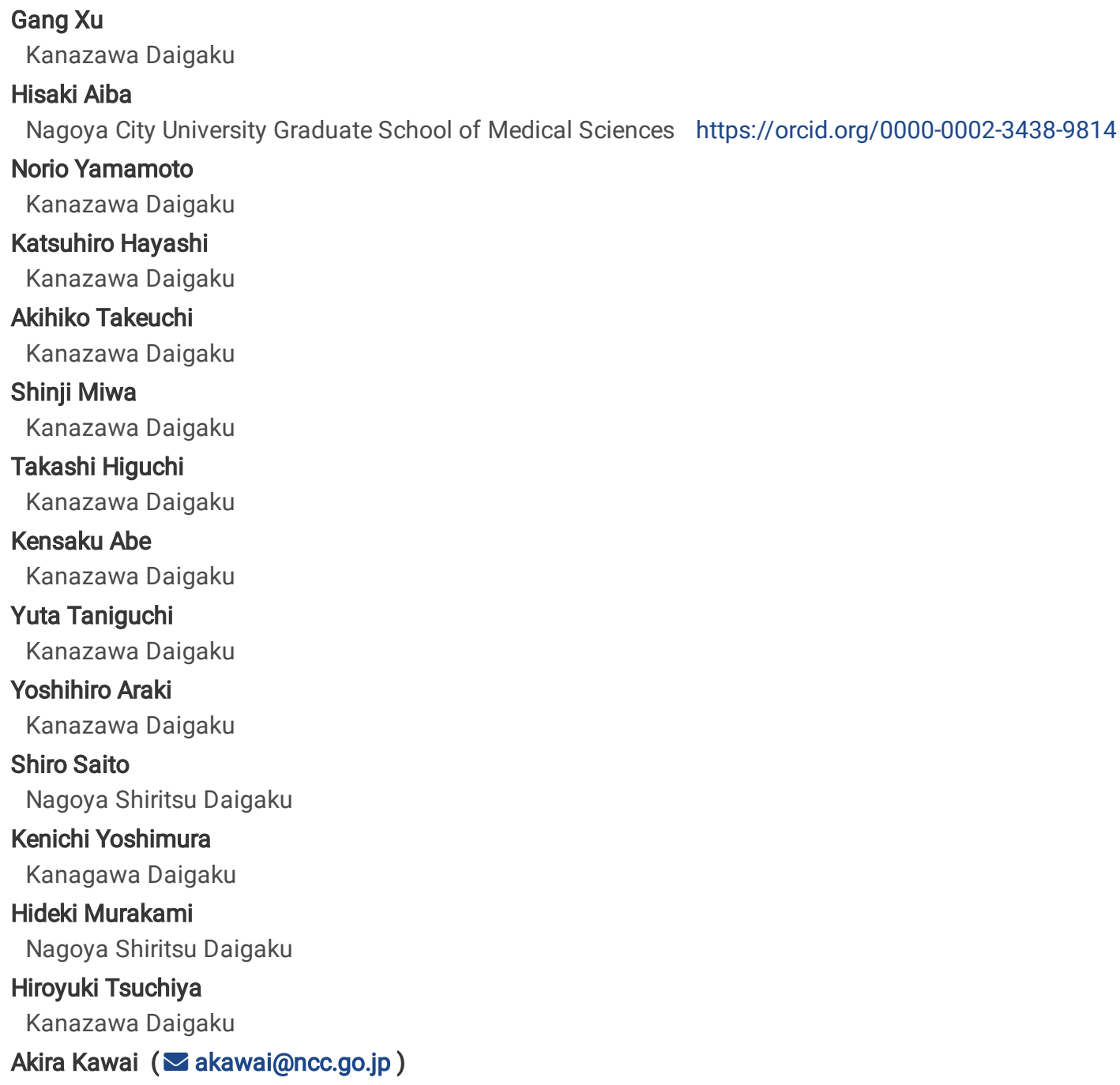

Akira Kawai ( $\square$ akawai@ncc.go.jp )

\section{Research article}

Keywords: Neoadjuvant therapy, chemotherapy, soft-tissue sarcoma, synovial sarcoma, database study, matched-pair analysis

Posted Date: May 27th, 2020

DOI: https://doi.org/10.21203/rs.3.rs-30261/v1

License: (c) (i) This work is licensed under a Creative Commons Attribution 4.0 International License. Read Full License 


\section{Abstract}

\section{Background}

Synovial sarcoma is an aggressive but chemosensitive soft-tissue tumor. We retrospectively analyzed the efficacy of neoadjuvant chemotherapy for synovial sarcoma with data from the nationwide database, Bone and Soft Tissue Tumor Registry in Japan.

\section{Methods}

This study included 316 patients diagnosed with synovial sarcoma between 2006 and 2012. Oncologic outcomes were analyzed using a Coxhazard regression model. The effects of neoadjuvant chemotherapy on outcomes were evaluated using a matched-pair analysis. The oncologic outcomes of patients who did or did not receive neoadjuvant chemotherapy were compared (cx+ and cx-).

\section{Results}

Multivariate analysis revealed significant correlations of distant postoperative metastasis (hazard ratio [HR] $=0.01, p<0.001)$ with overall survival; surgical margin type (marginal resection, $\mathrm{HR}=0.12, p=0.011$ and intralesional resection, $\mathrm{HR}=0.08, p=0.022$ versus wide resection) with local recurrence; and postoperative local recurrence $(\mathrm{HR}=0.30, p=0.027)$ and surgical margin (marginal resection, $\mathrm{HR}=0.31, p=0.023$ versus wide resection) with distant relapse-free survival.

Before propensity score matching, neoadjuvant chemotherapy was mainly administered for the patients with younger age, deeper tumor locations, larger tumors, more advanced-stage disease, and monophasic-type disease. The 3-year overall survival rates, local control rates and distant relapse-free survival rates were 82.9\% / 80.7\% ( $\mathrm{HR}=0.79, p=0.102), 91.2 \% / 89.8 \%(\mathrm{HR}=1.04, p=0.837)$ and $76.6 \% / 75.0 \%(\mathrm{HR}=$ $0.76, p=0.307)$ in the $c x+/ c x$ - groups, respectively. After propensity score matching, 172 patients were selected such that the patient demographics were nearly identical for both the groups. The 3-year overall survival rates, local control rates and distant relapse-free survival rates were $80.8 \% / 81.4 \%(\mathrm{HR}=0.83, p=0.563), 93.2 \% / 89.4 \%(\mathrm{HR}=0.83, p=0.491)$ and $76.9 \% / 78.7 \%(\mathrm{HR}=1.01, p=0.982)$ in the $\mathrm{cx}+\mathrm{and}$ cx-group, respectively.

\section{Conclusion}

This large-sample study indicated that the margin status and postoperative disease control were associated directly or indirectly with improved oncologic outcomes. However, the efficacy of neoadjuvant chemotherapy for survival outcomes in synovial sarcoma patients was not proven.

\section{Background}

Synovial sarcoma (SS), an aggressive mesenchymal tumor with high rates of local recurrence and metastasis, accounts for $5-10 \%$ of softtissue sarcomas (STSs). SS occurs most frequently in adolescents and young adults, and the median patient age at diagnosis is 35 years [16]. These tumors can be divided into three histologic subtypes: monophasic tumors, which are composed of spindle cells; biphasic tumors, which are composed of spindle cells and epithelial cells; and poorly differentiated tumors, which are composed of small round cells [4]. SS is considered to be chemosensitive [4, 7], and wide excision with a negative margin is necessary for effective treatment [8-10]. Therefore, the administration of neoadjuvant chemotherapy might be a rational approach to reduce micro-invasion from the primary site. However, chemotherapy for SS remains controversial because it is difficult to conduct a prospective study on the efficacy of neoadjuvant therapy, specifically for this tumor type. Moreover, several pretreatment characteristics, including the tumor size, age, histologic grade, and tumor depth $[6,9,11,14-16]$, influence the prognosis of a patient with SS and may have affected the results of previous studies.

We designed this study based on a matched-pair analysis (MPA) to clarify the role of neoadjuvant chemotherapy in the prognosis of SS patients. For a secondary analysis, we conducted subgroup analyses to detect populations that might benefit from neoadjuvant chemotherapy.

\section{Methods}

\section{Patient selection}

We extracted patient data from the Bone and Soft Tissue Tumor (BSTT) Registry of Japan, a nationwide organ-specific cancer registry for bone and soft-tissue tumors. Eighty-nine Japanese Orthopedic Association (JOA)-certified hospitals that specialize in musculoskeletal oncology participated obligatorily in this registry, and other hospitals participated voluntarily. The annual reports published by the BSTT include patient characteristics, such as basic data (sex, age, date of diagnosis, and treatment status at first visit [history of treatment in previous hospitals], tumor data (diagnosis, histologic details [malignant or benign disease and histologic grade for malignant tumors]), tumor location, data required for TNM staging (American Joint Committee on Cancer staging system, 7th edition), surgical data (date of definitive surgery, type of 
surgery, reconstruction details, and additional surgeries for complications), and information about additional treatments (chemotherapy, radiotherapy, and hyperthermia) [17].Follow-up surveys were conducted to collect information after 2, 5, and 10 years following the initial registration. These surveys included items about several types of outcomes, such as local recurrence, distant metastasis, and oncologic outcomes, at the time of the latest follow-up. This study was approved by the Institutional Review Board of the JOA.

From the BSTT registry, we identified 579 patients who were diagnosed with SS between 2006 and 2012. Of these, we excluded 133 patients who did not undergo primary tumor resection, 53 patients with missing data, and 77 patients with metastatic lesions. The final analysis dataset included 316 patients (Fig. 1).

\section{Statistical analysis}

The primary objective of this study was to investigate the following oncologic outcomes: overall survival (OS), defined as the time from diagnosis to death from any cause; distant relapse-free survival (D-RFS), defined as the time from surgery to distant progression or death; and local control (LC), defined as the time from surgery to local recurrence. Standardized intergroup differences were calculated using KaplanMeier and log-rank analyses. Potential risk factors for oncologic outcomes were analyzed with a step-wise Cox proportional hazards model, and hazard ratios (HRs) were calculated from these data.

We divided patients into two groups based on treatment with or without neoadjuvant chemotherapy (cx + versus cx- group). For the MPA, data on statistical variables, including age, sex, tumor location, tumor size, tumor histology, tumor depth, and administration of neoadjuvant chemotherapy, were obtained from the BSTT registry. A multivariate logistic regression analysis was conducted to determine associations between these factors and the administration of neoadjuvant chemotherapy. Propensity scores were calculated using a logistic regression model that included the weights of the contributions of each patient's demographic data. After calculating these scores, we propensity scorematched patients in a 1:1 ratio by using a nearest-neighbor algorithm, allowing a maximum tolerated difference of $\leq 30 \%$ between propensity scores [18]. All statistical analyses were conducted in SPSS version 25 (IBM Corp., Armonk, NY, USA). A two-sided $p$-value < 0.05 was considered statistically significant.

\section{Results}

This analysis included 316 patients (age, mean \pm SD, 38.8 \pm 18.2 ; males, 153 [48.3\%]; females, 163 [51.7\%]). The tumors were located in the lower extremities, upper extremities, trunk, and head/neck in 160 (50.5\%), 56 (17.7\%), 93 (29.3\%), and 7 (2.2\%) patients, respectively. Furthermore, the tumor subtypes were monophasic, biphasic, and unclassified/undifferentiated in 153 (48.3\%), 89 (28.2\%), and 74 (23.4\%) patients, respectively. The median (interquartile range; IQR) tumor size was $5.4 \mathrm{~cm}(3.4-9.0 \mathrm{~cm})$. The tumor stages were la-b, Ila-b, and III in 12 (3.8\%), 157 (49.5\%), and 147 (46.4\%) patients, respectively.

\section{Oncologic outcomes}

\section{Overall survival}

The included patients had OS rates of $83.5 \%( \pm 2.6)$ at 3 years and $66.8 \%( \pm 4.5)$ at 5 years. In the univariate analysis, sex, tumor subtype, tumor depth, tumor size, and tumor location had no significant impact on the OS. However, postoperative local recurrence $(\mathrm{HR}=0.33, p<$ 0.001), postoperative distant metastasis ( $\mathrm{HR}=0.01, p<0.001)$, and surgical margin type (marginal resection, $\mathrm{HR}=0.16, p<0.001$; intralesional resection, $\mathrm{HR}=0.29, p=0.016$ versus wide resection) were associated significantly with a poorer outcome. However, only postoperative distant metastasis was retained in the multivariate analysis (Table 1). 
Table 1

Results of univariate and multivariate analyses of oncologic outcomes

\begin{tabular}{|c|c|c|c|c|}
\hline Characteristics & $\mathrm{HR}(95 \% \mathrm{Cl})$ & $P$-value & $\mathrm{HR}(95 \% \mathrm{Cl})$ & $P$-value \\
\hline Overall survival & Univariate analysis & & Multivariate analysi & \\
\hline Sex (male < female) & $0.70(0.42-1.08)$ & 0.104 & NS & NS \\
\hline Subtype (Unclassified < Biphasic) & $0.57(0.27-1.21)$ & 0.143 & NS & NS \\
\hline Subtype (Monophasic < Biphasic) & $0.82(0.45-1.51)$ & 0.529 & NS & NS \\
\hline Depth (Superficial < Deep) & $0.59(0.24-1.48)$ & 0.263 & NS & NS \\
\hline Tumor size $(>5 \mathrm{~cm})$ & $0.73(0.42-1.29)$ & 0.277 & NS & NS \\
\hline Tumor location (Upper < Lower extremity) & $0.81(0.47-1.41)$ & 0.811 & NS & NS \\
\hline $\begin{array}{l}\text { Tumor location } \\
\text { (Trunk + head and neck < Lower extremity) }\end{array}$ & $0.81(0.39-1.68)$ & 0.813 & NS & NS \\
\hline Postoperative local recurrence & $0.33(0.17-0.65)$ & $<0.01$ & NS & NS \\
\hline Postoperative distant metastasis & $0.01(0.002-0.04)$ & $<0.01$ & $0.01(0.002-0.04)$ & $<0.01$ \\
\hline Surgical margin (Marginal < Wide) & $0.16(0.07-0.36)$ & $<0.01$ & NS & NS \\
\hline Surgical margin (Intralesional < Wide) & $0.29(0.11-0.79)$ & 0.016 & NS & NS \\
\hline Local control & Univariate analysis & & Multivariate analysi & \\
\hline Sex (male < female) & $0.94(0.42-2.49)$ & 0.940 & NS & NS \\
\hline Subtype (Unclassified < Biphasic) & $0.58(0.17-2.70)$ & 0.580 & NS & NS \\
\hline Subtype (Monophasic < Biphasic) & $0.82(0.32-3.12)$ & 0.990 & NS & NS \\
\hline Depth (Superficial < Deep) & $0.33(0.04-2.49)$ & 0.284 & NS & NS \\
\hline Tumor size (> $5 \mathrm{~cm})$ & $0.61(0.22-1.70)$ & 0.340 & NS & NS \\
\hline Tumor location (Upper < Lower extremity) & $0.76(0.28-2.05)$ & 0.592 & NS & NS \\
\hline $\begin{array}{l}\text { Tumor location } \\
\text { (Trunk + head and neck < Lower extremity) }\end{array}$ & $0.67(0.17-2.58)$ & 0.557 & NS & NS \\
\hline Surgical margin (Marginal < Wide) & $0.12(0.04-0.36)$ & 0.011 & $0.12(0.04-0.36)$ & 0.011 \\
\hline Surgical margin (Intralesional < Wide) & $0.08(0.01-0.70)$ & 0.022 & $0.08(0.01-0.70)$ & 0.022 \\
\hline Distal recurrent survival & Univariate analysis & & Multivariate analysi & \\
\hline Sex (male < female) & $0.60(0.36-1.01)$ & 0.053 & NS & NS \\
\hline Subtype (Unclassified < Biphasic) & $0.57(0.27-1.24)$ & 0.160 & NS & NS \\
\hline Subtype (Monophasic < Biphasic) & $0.86(0.46-1.61)$ & 0.640 & NS & NS \\
\hline Depth (Superficial < Deep) & $0.53(0.21-1.31$ & 0.284 & NS & NS \\
\hline Tumor size (> $5 \mathrm{~cm})$ & $0.62(0.35-1.11)$ & 0.340 & NS & NS \\
\hline Tumor location (Upper < Lower extremity) & $0.80(0.45-2.05)$ & 0.592 & NS & NS \\
\hline $\begin{array}{l}\text { Tumor location } \\
\text { (Trunk + head and neck < Lower extremity) }\end{array}$ & $0.81(0.39-1.70)$ & 0.557 & NS & NS \\
\hline Postoperative local recurrence & $0.33(0.16-0.71)$ & 0.004 & $0.30(0.17-0.90)$ & 0.027 \\
\hline Surgical margin (Marginal $<$ Wide) & $0.21(0.08-0.54)$ & 0.001 & $0.31(0.11-0.85)$ & 0.023 \\
\hline Surgical margin (Intralesional < Wide) & $0.46(0.15-1.38)$ & 0.105 & $0.71(0.21-2.34)$ & 0.571 \\
\hline
\end{tabular}




\section{Local control}

The postoperative local recurrence rates were $9.1 \%( \pm 2.1)$ at 3 years and $11.1 \%( \pm 2.9 \%)$ at 5 years. On univariate analysis, sex, tumor subtype, tumor depth, tumor size, and tumor location had no significant effects on LC. Moreover, surgical margins (marginal resection, HR $=0.12, p=$ 0.011 ; intralesional resection, $\mathrm{HR}=0.08, p=0.022$, compared with wide resection) were significantly associated with local recurrence. These trends were retained on multivariate analysis (Table 1 ).

\section{Distant relapse-free survival}

Patients in our sample had D-RFS rates of $80.2 \%( \pm 2.7)$ at 3 years and $68.7 \%( \pm 4.5)$ at 5 years. On univariate analysis, sex, tumor subtype, tumor depth, tumor size, and tumor location had no significant effect on D-RFS. However, significant associations with postoperative local recurrence $(\mathrm{HR}=033, p=0.004)$ and inadequate surgical margin (marginal resection, $\mathrm{HR}=0.21, p<0.01$, compared with wide resection) were identified, and these remained significant on multivariate analysis (Table 1).

Before adjustment with the propensity score, we observed some differences between patients who did $(n=151)$ or did not $(n=165)$ receive neoadjuvant chemotherapy; particularly, the former group tended to be younger and to have deeper tumor locations, larger tumors, more advanced-stage disease, and monophasic-type disease (Table 2). Among the patients in the cx + group, 101 (66.9\%) underwent neoadjuvant chemotherapy with the $\mathrm{Al}$ (doxorubicin and ifosfamide) regimen or another doxorubicin-containing regimen, together with cisplatin, ifosfamide, dacarbagin, or vincristine. The 3-year OS rates were $82.9 \%( \pm 3.6 \%)$ in the $\mathrm{cx}+$ group and $80.7 \%( \pm 2.9 \%)$ in the $\mathrm{cx}-\mathrm{group}(\mathrm{HR}=0.79[0.49-1.28]$, $p=0.102)$, and the 3-year LC rates were $91.2 \%( \pm 2.9 \%)$ in the $\mathrm{cx}+$ group and $89.8 \%( \pm 3.4 \%)$ in the cx- group (HR=1.04 [0.43-2.50], $p=0.837)$. The 3-year D-RFS rates were 76.6\% $( \pm 3.9 \%)$ in the $\mathrm{cx}+$ group and $75.0 \%( \pm 4.3 \%)$ in the cx-group $(\mathrm{HR}=0.76[0.46-1.28], p=0.307, \mathrm{Fig} .2)$.

Table 2

Patient characteristics before the matched-pair analysis

\begin{tabular}{|c|c|c|c|c|c|c|c|}
\hline & & \multicolumn{3}{|c|}{ Before matching $(\mathrm{N}=316)$} & \multicolumn{3}{|c|}{ After matching ( $N=172)$} \\
\hline & & $\begin{array}{l}\text { Chemotherapy } \\
(n=151)\end{array}$ & $\begin{array}{l}\text { No } \\
\text { chemotherapy } \\
(n=165)\end{array}$ & $\begin{array}{l}\mathrm{P} \text { - } \\
\text { value }\end{array}$ & $\begin{array}{l}\text { Chemotherapy } \\
(n=86)\end{array}$ & $\begin{array}{l}\text { No } \\
\text { chemotherapy } \\
(n=86)\end{array}$ & $\begin{array}{l}\mathrm{P} \text { - } \\
\text { value }\end{array}$ \\
\hline Sex & Male/female & $72 / 79$ & $81 / 84$ & $0.802^{\mathrm{a}}$ & $41 / 45$ & $46 / 40$ & $0.446^{\mathrm{a}}$ \\
\hline $\begin{array}{l}\text { Age, } \\
\text { years }\end{array}$ & $\begin{array}{l}<20 / 20-40 / 40-60 />60 \\
\text { Median, IQR }\end{array}$ & $\begin{array}{l}30 / 75 / 34 / 12 \\
30(20-42)\end{array}$ & $\begin{array}{l}20 / 50 / 59 / 36 \\
44(30-58)\end{array}$ & $\begin{array}{l}< \\
0.001 \\
b\end{array}$ & $23 / 36 / 19 / 8$ & $35 / 32 / 12 / 7$ & $0.225^{\mathrm{b}}$ \\
\hline Depth & Superficial/deep & $14 / 137$ & $31 / 134$ & $0.016^{a}$ & $11 / 75$ & $13 / 73$ & $0.660^{\circ}$ \\
\hline Location & $\begin{array}{l}\text { Trunk/head and neck/upper } \\
\text { extremity /lower extremity }\end{array}$ & $55 / 4 / 26 / 66$ & $38 / 3 / 30 / 94$ & $0.05^{\mathrm{a}}$ & $24 / 1 / 16 / 45$ & $22 / 15 / 48 / 1$ & $0.975^{\mathrm{a}}$ \\
\hline $\begin{array}{l}\text { Length } \\
\text { of } \\
\text { tumor, } \\
\mathrm{cm}\end{array}$ & $\begin{array}{l}<5 / 5-10 / 10-15 />15 \\
\text { Median, IQR }\end{array}$ & $\begin{array}{l}34 / 76 / 34 / 7 \\
7.0(5.0-10.0)\end{array}$ & $\begin{array}{l}83 / 53 / 20 / 9 \\
4.5(3.0-7.1)\end{array}$ & ${ }^{<} 0.001^{b}$ & $23 / 36 / 19 / 8$ & $35 / 32 / 12 / 7$ & $\begin{array}{l}0.225 \\
b\end{array}$ \\
\hline Stage & $\mathrm{I} / \mathrm{II} / \mathrm{III}$ & $4 / 55 / 92$ & $8 / 102 / 55$ & $\begin{array}{l}< \\
0.001^{a}\end{array}$ & $3 / 44 / 39$ & $3 / 41 / 42$ & $\begin{array}{l}0.514 \\
a\end{array}$ \\
\hline Subtype & Monophasic/biphasic/unclassified & $63 / 51 / 37$ & $90 / 38 / 37$ & $0.033^{a}$ & $37 / 27 / 3 / 19$ & $50 / 21 / 3 / 12$ & $0.233^{a}$ \\
\hline \multicolumn{8}{|c|}{${ }^{\mathrm{a}}$ chi-square test, ${ }^{\mathrm{b}}$ Mann-Whitney U test. } \\
\hline
\end{tabular}

After propensity score matching, 172 patients were selected such that the patient demographics were nearly identical for both the groups (Table 2). The 3-year OS rates were $80.8 \%( \pm 5.0 \%)$ in the $\mathrm{cx}+$ group and $81.4 \%( \pm 5.0 \%)$ in the cx- group $(\mathrm{HR}=0.83$ [0.43-1.57], $p=0.563)$, and the 3-year LC rates were $93.2 \%( \pm 3.4 \%)$ in the $c x+$ group and $89.4 \%( \pm 4.2 \%)$ in the cx-group $(\mathrm{HR}=0.83$ [0.25-2.73], $p=0.491)$. The 3-year DRFS rates were $76.9 \%( \pm 5.3 \%)$ in the $c x+$ group and $78.7 \%( \pm 5.1 \%)$ in the $c x-$ group $(H R=1.01[0.53-1.92], p=0.982$, Fig. 2$)$.

\section{Discussion}


Definitive treatment strategies for STSs, which vary based on histological characteristics, have not been fully determined. Moreover, the various subtypes of STS are rare, and it is difficult to deduce meaningful results. Therefore, we analyzed data from the largest soft-tissue tumorspecific database in Japan to determine the risk factors associated with SS outcomes. Notably, we identified distant metastasis after primary resection, surgical margins, and local recurrence after primary resection and surgical margins as risk factors that affect the oncologic outcomes of OS, LC, and D-RFS, respectively. In contrast, previous studies had identified distant metastasis at diagnosis, SS subtype (poorly differentiated < biphasic type and monophasic < biphasic type), tumor depth (deep < superficial), tumor size (>5 cm), and local recurrence as independent prognostic factors $[6,7,9,14-16]$. These findings indicated the importance of complete surgical resection to avoid micro/macroresidues of the tumor in the post-resection margins. To verify improvements in the surgical outcome, we further attempted to demonstrate the efficacy of neoadjuvant chemotherapy for SS by comparing the oncologic outcomes between the cx + and cx- groups.

Theoretically, neoadjuvant therapy for locally advanced and high-risk STS has several advantages over adjuvant chemotherapy. First, this modality could potentially reduce possible invasion around the tumor and thus prevent micro-residual resection. In cases where a tumor arises near neurovascular bundles, neoadjuvant chemotherapy improves the likelihood that resection will spare the neurovascular bundles and may allow the patient to forgo amputation, which allows the preservation of muscle function [22]. Second, neoadjuvant chemotherapy can potentially improve patient survival by eradicating micro-metastatic disease without delaying adjuvant chemotherapy. Finally, neoadjuvant therapy can provide guidance for postoperative therapeutic strategies.

Currently, the role of neoadjuvant chemotherapy in SS remains controversial [19] because of the challenges associated with prospective studies and the potential for various selection biases in retrospective studies. Therefore, to reduce the possible bias of the retrospective analysis, we examined the oncologic outcomes of SS using an MPA of a relatively large population and thus present a novel report. We found that the $c x+$ population was more likely to have monophasic-type disease, a large tumor size, and distant metastasis at diagnosis, suggesting that selection bias might affect the oncologic outcomes. However, we did not observe a significant difference in the oncologic outcomes of patients in the cx + and cx-groups, despite propensity matching to reduce intergroup differences. Possibly, similar numbers of patients in both groups derived benefits from chemotherapy. Although we did not identify significant intergroup differences, our data suggested that patients with large tumors ( $>5 \mathrm{~cm}$ ) and those with monophasic-type disease would benefit from neoadjuvant chemotherapy (Appendices A and B). These characteristics might affect oncologic outcomes and may explain the controversial results of previous reports.

In a previous study of the analysis of resectable SS, the 5-year OS rate was 64\%, and age > 35 years, Grade 3 tumor, and margins other than R0 were identified as significant independent predictive factors for improved survival. Despite adjustments based on these factors, we did not observe any significant impact of chemotherapy on survival in the present analysis. The HRs for OS with neoadjuvant chemotherapy and adjuvant therapy were $1.01(p=0.358)$ and $1.62(p=0.099)$, respectively [12]. Similarly, $52 \%$ of patients with localized SS in an Italian study were treated with a combination of ifosfamide and doxorubicin or epirubicin, and the 5-year OSs of those who did or did not receive chemotherapy were $69 \%$ and $82 \%$, respectively $(p=0.20)$. In that study, the negative impact of chemotherapy was explained by the exclusive administration of this treatment modality to patients with larger tumors $(>5 \mathrm{~cm})$ and re-excision cases. These preconditions may have influenced the outcomes [9].

In contrast, an analysis of 14 trials reported that doxorubicin-based chemotherapy significantly improved oncologic outcomes. Although the SS subgroup extracted from these trials was better oriented for chemotherapy, that analysis identified no significant improvement in 0S (57.5\% and $47.3 \%$ for the chemotherapy and control groups, respectively) [20]. Eilber et al. reported favorable outcomes with ifosfamide-based chemotherapy for SS in a dataset limited to patients with tumors $>5 \mathrm{~cm}$, deep tumors, as well as primary and extremity tumors and were treated between 1990 and 2002. In that study, the 4-year disease-specific survival rates were $88 \%$ and $67 \%$ in the chemotherapy and nochemotherapy groups, respectively $(p=0.01)$. Additionally, treatment with an ifosfamide-based regimen was reported to improve $\mathrm{D}-\mathrm{RFS}(\mathrm{HR}=$ $0.4, p=0.03$ ) [13]. Ferrari et al. suggested that younger patients and those with tumors larger than $>5 \mathrm{~cm}$ achieved better outcomes with chemotherapy [21]. These retrospective studies indicate that high-risk patients might benefit from neoadjuvant chemotherapy, which supports our findings.

Few published reports have focused on neoadjuvant therapy for the treatment of SS. One randomized phase 2 trial of adult patients with highrisk STS (tumor size $>8 \mathrm{~cm}$ of any grade, tumor size $<8 \mathrm{~cm}$ of grade $2 / 3$, or locally recurrent sarcoma/after inadequate surgery of grade $2 / 3$ ) did not indicate that a regimen of three cycles of neoadjuvant chemotherapy was superior to surgery alone in patients (5-year disease-free survival rates of $56 \%$ and $52 \%$ for the neoadjuvant chemotherapy and surgery-alone arms, respectively; $p=0.354$ ) [23]. With regard to the comparison between neoadjuvant and adjuvant chemotherapy, a retrospective analysis reported that neoadjuvant chemotherapy (doxorubicin + ifosfamide + dacarbazine) for SS had a significant advantage over adjuvant chemotherapy (5-year OS rates of $84.5 \%$ and $55.6 \%$ for the neoadjuvant chemotherapy and adjuvant chemotherapy groups, respectively) [3]. However, that study did not sufficiently balance patients who received neoadjuvant chemotherapy with those who received adjuvant therapy. Therefore, it remains difficult to draw meaningful conclusions on the actual contribution of neoadjuvant chemotherapy to patient outcomes. 
This study had several limitations. First, the design was retrospective and, therefore, many biases, including selection and recall bias, may have influenced the results despite a propensity-score adjustment. Second, the BSTT database covers only patients treated at orthopedic departments; thus, our dataset did not include patients treated at other departments. Third, we could not evaluate the exact intensity of chemotherapy. Consequently, patients who received attenuated chemotherapy were included in the cx + group. Fourth, we did not analyze differences in genotype. As fusion proteins resulting from the SYT-SSY1 or SYT-SSY2 fusions have been associated with the histological subtype and clinical behavior, these biomarkers should be reviewed in a further analysis of this database [24]. Finally, in Japan, the standard treatment protocol for SS involves a doxorubicin-based chemotherapy regimen. However, the different participating institutions do not use identical protocols. Accordingly, although $60.1 \%$ of patients received neoadjuvant chemotherapy via the Al regimen, many patients were treated with Al-IE, VDC/IE, MAID, or other regimens. These differences might have affected the study outcomes. We further note that, currently, new drugs are being approved rapidly in Japan, and pazopanib, trabectedin, and eribulin have been proven to yield improved oncologic outcomes in patients. These newly approved drugs may influence patient outcomes and, therefore, potential changes in treatment strategy should be considered when applying our findings.

\section{Conclusion}

We analyzed a large population database in Japan to determine the factors that affect the oncologic outcomes of patients with non-metastatic SS. Notably, we found that the margin status and postoperative local control were associated directly or indirectly with improvements in oncologic outcomes. However, we did not find a significant contribution of neoadjuvant therapy to survival outcomes in either the non-adjusted or propensity score-matched populations.

\section{Abbreviations}

Al: Adriamycin + Ifosfamide; BSTT:Bone and Soft Tissue Tumor; cx:neoadjuvant chemotherapy; D-RFS:distant relapse-free survival; HR:hazard ratio; IE:Ifosfamide + Etoposide; IQR:interquartile range; JOA:Japanese Orthopedic Association; LC:local control; MAID:Mesna + Doxorubicin + Ifosfamide + Dacarbazine; MPA:matched-pair analysis; OS:overall survival; STS:soft-tissue sarcomas; SS:synovial sarcoma; VDC:Vincristine + Doxorubicin + Cyclophosphamide.

\section{Appendices}

Appendix A: Kaplan-Meier analysis including only patients with monophasic-type disease

Appendix B: Kaplan-Meier analysis including only patients with large tumors $(>5 \mathrm{~cm})$

\section{Declarations}

\section{Ethics approval and consent to participate}

This retrospective study was conducted in comph2ance with the tenets of the Declaration of Helsinki of 1964 and its subsequent amendments. Furthermore, the use of the BSTT database was approved by the Institutional Review Board of the Japanese Orthopedic Association.

\section{Consent for publication.}

Because the database is de-identified, informed consent was not mandated by the Ethics Guideh2nes for Human Subject Medical Research, and this requirement was waived by the Institutional Review Board.

\section{Availabih2ty of data and materials.}

The datasets supporting the conclusion of this article are available on request to the Japanese Orthopedic Association committee.

\section{Competing interests.}

The authors declare that they have no confh2cts of interest. 


\section{Funding.}

No financial support was received for this study.

\section{Authors' contributions}

GX, conception and drafting of the work; HA, conception, design of the work, acquisition, analysis, interpretation of data, the creation of new software used in the work, drafted the work or substantively revised it; NY, acquisition, analysis, and interpretation of data; KH, acquisition, analysis, and interpretation of data; $\mathrm{AT}$, acquisition, analysis, and interpretation of data; SM, acquisition, analysis, and interpretation of data; $\mathrm{TH}$, interpretation of data; KA, acquisition, analysis, and interpretation of data; $\mathrm{YT}$, acquisition, analysis, and interpretation of data; $\mathrm{YA}$, acquisition, analysis, and interpretation of data; SS, acquisition, analysis, and interpretation of data; KY, acquisition, analysis, and interpretation of data; $\mathrm{HM}$, acquisition, analysis, and interpretation of data; $\mathrm{HT}$, acquisition, analysis, and interpretation of data; interpretation of data; $\mathrm{AK}$, study conception, study design, and interpretation of data.

\section{References}

1. Deshmukh R, Mankin HJ, Singer S. Synovial sarcoma: the importance of size and location for survival. Clin Orthop Relat Res. 2004;419:155-61.

2. Vining CC, Sinnamon AJ, Ecker BL, Kelz RR, Fraker DL, Roses RE, Karakousis GC. Adjuvant chemotherapy in resectable synovial sarcoma.ã⿰J. Surg Oncol. 2017;116:550-8.

3. Wu Y, Bi W, Han G, Jia J, Xu M. Influence of neoadjuvant chemotherapy on prognosis of patients with synovial sarcoma. World J Surg Oncol 2017;11:15:101. https://doi: 10.1186/s12957-017-1165-9.

4. Spurrell EL, Fisher C, Thomas JM, Judson IR. Prognostic factors in advanced synovial sarcoma: an analysis of 104 patients treated at the Royal Marsden Hospital. Ann Oncol. 2005;16:437-44.

5. Eilber FC, Dry SM. Diagnosis and management of synovial sarcoma. J Surg Oncol. 2008;97:314-20.

6. Yaser S, Salah S, A-Shatti M, et al Abu-Sheikha A, Shehadeh A, Sultan I, Salem A, Sughayer M, Al-Loh S, Al-Mousa A. Prognostic factors that govern localized synovial sarcoma: a single institution retrospective study on 51 patients. Med Oncol. 2014;31:958.

7. Okcu MF, Munsell M, Treuner J, Mattke A, Pappo A, Cain A, Ferrari A, Casanova M, Ozkan A, Raney B. Synovial sarcoma of childhood and adolescence: a multicenter, multivariate analysis of outcome. J Clin Oncol. 2003;21:1602-11.

8. Chakiba C, Lagarde P, Pissaloux D, Neuville A, Brulard C, Pérot G, Coindre JM, Terrier P, Ranchere-Vince D, Ferrari A, Collini P, Suurmeijer AJ, Blay JY, Terrisse SA, Piperno-Neumann S, Averous G, Bui B, Orbach D, Italiano A, Chibon F. Response to chemotherapy is not related to chromosome instability in synovial sarcoma. Ann Oncol. 2014;25:2267-71.

9. Palmerini E, Staals EL, Alberghini M, Zanella L, Ferrari C, Benassi MS, Picci P, Mercuri M, Bacci G, Ferrari S. Synovial sarcoma: retrospective analysis of 250 patients treated at a single institution. Cancer. 2009;115:2988-2298.

10. Song S, Park J, Kim HJ, Kim IH, Han I, Kim HS, Kim S. Effects of Adjuvant Radiotherapy in Patients With Synovial Sarcoma. Am J Clin Oncol. 2017;40:306-11.

11. Ramu EM, Houdek MT, Isaac CE, Dickie Cl, Ferguson PC, Wunder JS. Management of soft-tissue sarcomas; treatment strategies, staging, and outcomes. SICOT J. 2017;3:20.

12. Italiano A, Penel N, Robin YM, Bui B, Le Cesne A, Piperno-Neumann S, Tubiana-Hulin M, Bompas E, Chevreau C, Isambert N, Leyvraz S, du Chatelard PP, Thyss A, Coindre JM, Blay JY. Neo/adjuvant chemotherapy does not improve outcome in resected primary synovial sarcoma: a study of the French Sarcoma Group. Ann Oncol. 2009;20:425-30.

13. Eilber FC, Brennan MF, Eilber FR, Eckardt JJ, Grobmyer SR, Riedel E, Forscher C, Maki RG. Singer S.Chemotherapy is associated with improved survival in adult patients with primary extremity synovial sarcoma. Ann Surg. 2007;24:105-13.

14. Biau DJ, Ferguson PC, Turcotte RE, Chung P, Isler MH, Riad S, Griffin AM, Catton CN, O'Sullivan B, Wunder JS. Adverse effect of older age on the recurrence of soft tissue sarcoma of the extremities and trunk. J Clin Oncol. 2011;29:4029-35.

15. Vlenterie M, Ho VK, Kaal SE, Vlenterie R, Haas R van der. Graaf WT1. Age as an independent prognostic factor for survival of localised synovial sarcoma patients. Br J Cancer. 2015;113:1602-6.

16. Oda Y, Hashimoto H, Tsuneyoshi M, Takeshita S. Survival in synovial sarcoma. A multivariate study of prognostic factors with special emphasis on the comparison between early death and long-term survival. Am J Surg Pathol. 1993;17:35-44.

17. Ogura K, Higashi T, Kawai A. Statistics of soft-tissue sarcoma in Japan: Report from the Bone and Soft Tissue Tumor Registry in Japan. J Orthop Sci. 2017;22:755-64. 
18. Nussbaum DP, Rushing CN, Lane WO, Cardona DM, Kirsch DG, Peterson BL, Blazer DG 3rd. Preoperative or postoperative radiotherapy versus surgery alone for retroperitoneal sarcoma: a case-control, propensity score-matched analysis of a nationwide clinical oncology database. Lancet Oncol. 2016;17:966-75.

19. Stacchiotti S, Van Tine BA. Synovial Sarcoma: Current Concepts and Future Perspectives. Clin Oncol. 2018;36:180-7.

20. Sarcoma Meta-analysis Collaboration. Adjuvant chemotherapy for localised resectable soft-tissue sarcoma of adults: meta-analysis of individual data. Lancet. 1997;350:1647-54.

21. Ferrari A, Gronchi A, Casanova M, Meazza C, Gandola L, Collini P, Lozza L, Bertulli R, Olmi P, Casali PG. Synovial sarcoma: a retrospective analysis of 271 patients of all ages treated at a single institution. Cancer. 2004;101:627-34.

22. Pasquali S, Gronchi A. Neoadjuvant chemotherapy in soft tissue sarcomas: latest evidence and clinical implications. Ther Adv Med Oncol. 2017;9:415-29.

23. Gortzak E, Azzarelli A, Buesa J, Bramwell VH, van Coevorden F, van Geel AN, Ezzat A, Santoro A, Oosterhuis JW, van Glabbeke M, Kirkpatrick A, Verweij J, E.O.R.T.C. Soft Tissue Bone Sarcoma Group and the National Cancer Institute of Canada Clinical Trials Group/Canadian Sarcoma Group. Soft Tissue Bone Sarcoma Group and the National Cancer Institute of Canada Clinical Trials Group/Canadian Sarcoma Group. A randomised phase II study on neo-adjuvant chemotherapy for 'high-risk' adult soft-tissue sarcoma. Eur J Cancer. 2001;37:1096-103.

24. Kawai A, Woodruff J, Healey JH, Brennan MF, Antonescu CR, Ladanyi M. SYT-SSX gene fusion as a determinant of morphology and prognosis in synovial sarcoma. N Engl J Med. 1998;15:338:153-60.

\section{Figures}

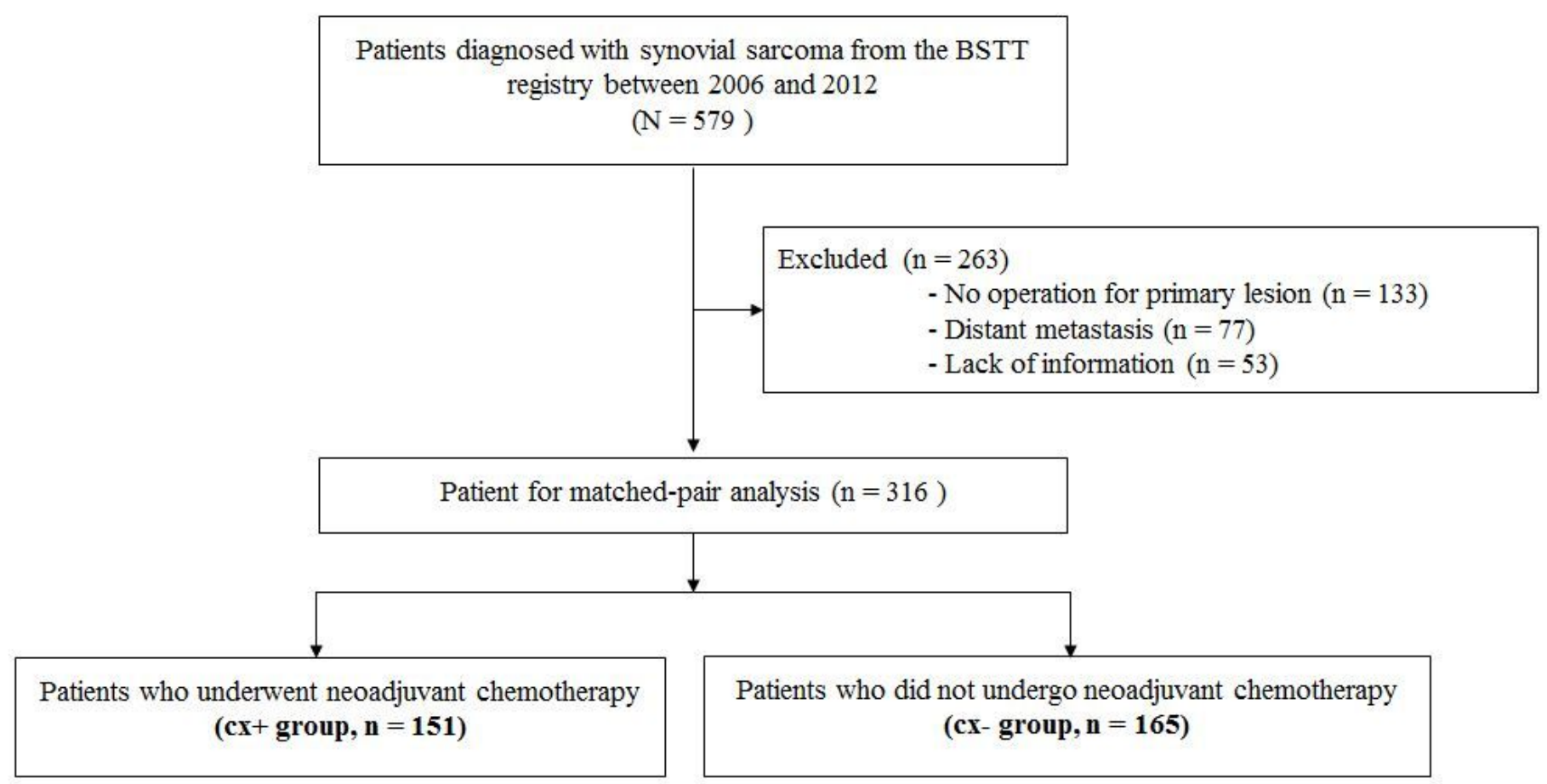

Figure 1

A CONSORT diagram of patient selection for this study. 
(a)

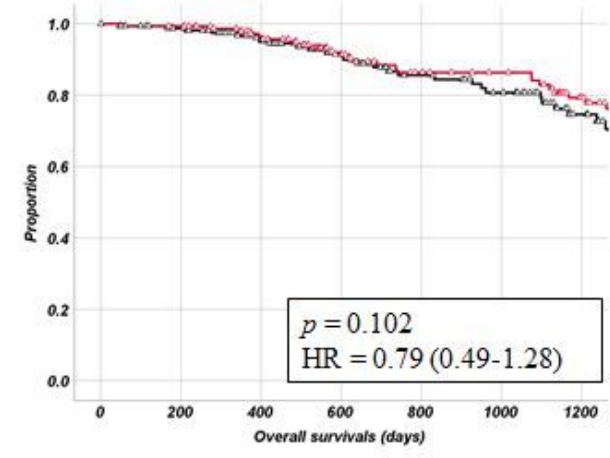

(d)

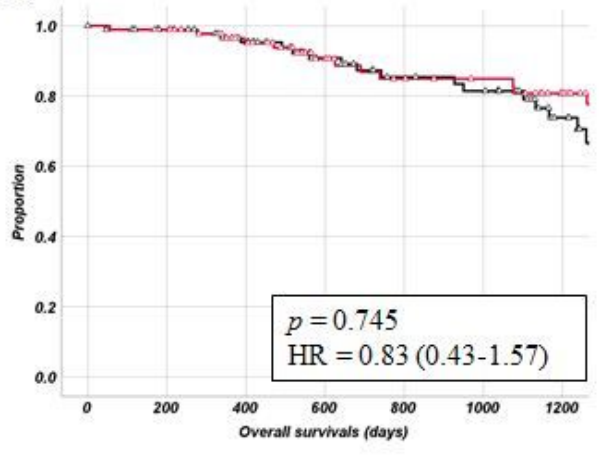

(b)

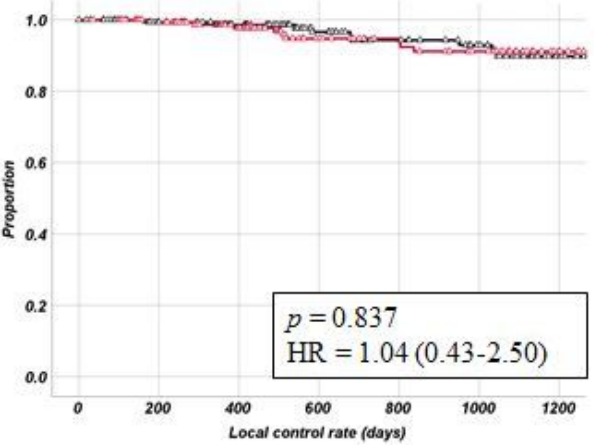

(e)

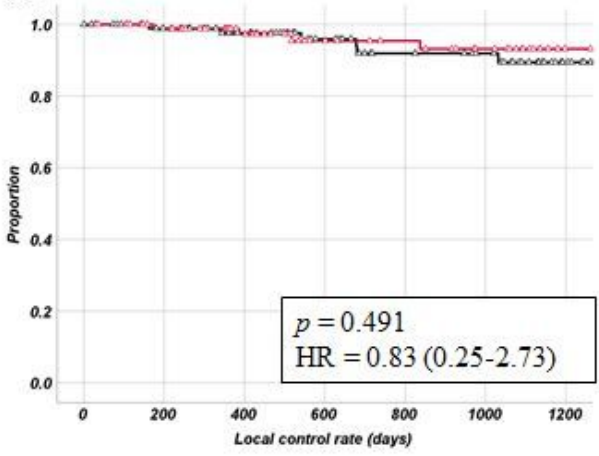

(c)

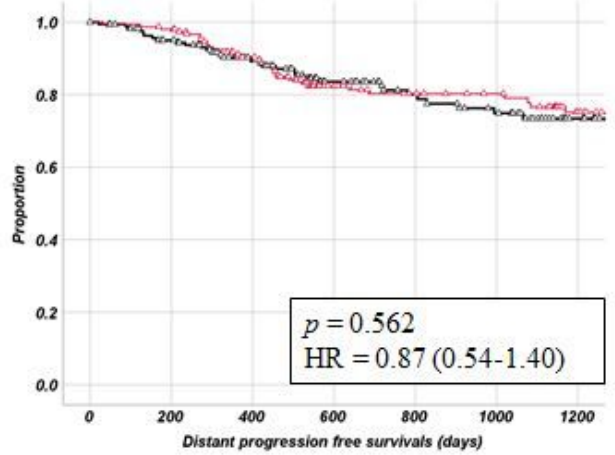

(f)

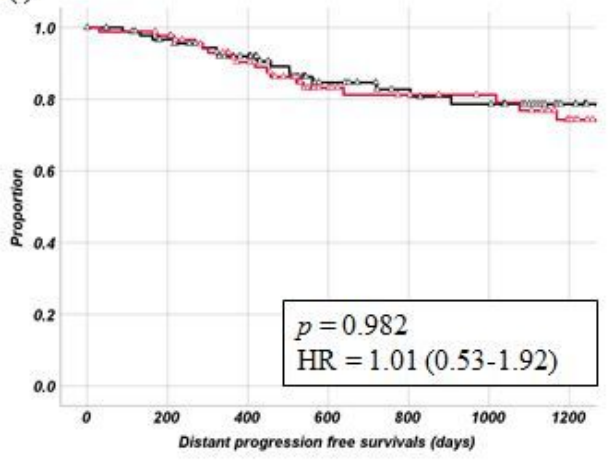

Figure 2

Kaplan-Meier analyses of the oncologic outcomes of patients who did (cx+) or did not (cx-) receive neoadjuvant chemotherapy (red curve: cx+ group, black curve: cx-group). a-c: outcomes before propensity-score matching ( $n=316)$; $d$-f: outcomes after propensity-score matching $(n=172)$. Triangles indicate the censored cases.

\section{Supplementary Files}

This is a list of supplementary files associated with this preprint. Click to download.

- additionalfigure1and2.docx 